\title{
Effect of Environmental Conditions on Flexural Strength and Fracture Toughness of Particulate Filled Glass-Epoxy Hybrid Composites
}

\author{
Basappa Hulugappa, Mysuru Venkataramaiah Achutha, Bheemappa Suresha* \\ Department of Mechanical Engineering, The National Institute of Engineering, Mysuru, India \\ Email: *suresha.b2005@gmail.com, *sureshab@2004yahoo.co.in, *sureshab@nie.ac.in
}

How to cite this paper: Hulugappa, B., Achutha, M.V. and Suresha, B. (2016) Effect of Environmental Conditions on Flexural Strength and Fracture Toughness of Particulate Filled Glass-Epoxy Hybrid Composites. Materials Sciences and Applications, 7, 710-729.

http://dx.doi.org/10.4236/msa.2016.711057

Received: October 7, 2016

Accepted: November 12, 2016

Published: November 15, 2016

Copyright $\odot 2016$ by authors and Scientific Research Publishing Inc. This work is licensed under the Creative Commons Attribution International License (CC BY 4.0).

http://creativecommons.org/licenses/by/4.0/ (c) (i) Open Access

\begin{abstract}
Multifunctional hybrid polymer composites were projected as novel solutions to meet the demands in various industrial applications ranging from automotive to aerospace. This investigation focuses on processing, flexural strength and fracture toughness characterization of the glass fabric reinforced epoxy (G-E) composites and graphite/fly ash cenosphere (FAC) modified interface between the epoxy matrix and glass fabric. Hand lay-up followed by compression moulding method was used to fabricate the laminates. Flexural and fracture toughness tests at room temperature, elevated temperature and cryogenic temperature were conducted to assess the flexural strength (FS) and mode-I plane-strain fracture toughness $\left(\mathrm{K}_{\mathrm{IC}}\right)$. The experimental and characterization efforts suggest that both graphite and FAC fillers improve bonding at the interface. The study showed that the graphite is more favorable for enhancing FS and $\mathrm{K}_{\mathrm{IC}}$ of G-E composites. Graphite filled G-E hybrid composites with significant FS and $\mathrm{K}_{\mathrm{IC}}$ to that of unfilled and FA filled G-E were successfully achieved by incorporating $10 \mathrm{wt} \%$ graphite. The incorporation of fillers resulted in improvement of FS, which increased by $43 \%$ and $37.7 \%$ for $10 \mathrm{Gr}+\mathrm{G}-\mathrm{E}$ and $10 \mathrm{FAC}+\mathrm{G}-\mathrm{E}$ hybrid composites respectively. All composites show a $26 \%$ improvement in $\mathrm{K}_{\mathrm{IC}}$ at cryogenic temperature and a decrease of $12.5 \%$ at elevated temperature. According to the SEM observations, fiber debonding from the matrix is suppressed due to the presence and uniform distribution of graphite. In addition, micro-pores, matrix shearing, active toughening mechanisms induced by graphite, such as crack deflection, layer breakage and delamination of graphite layers contributed to the enhanced $\mathrm{K}_{\mathrm{IC}}$ of hybrid G-E composites.
\end{abstract}

\section{Keywords}

Particulate Filled G-E, Flexural Strength, Plane-Strain Fracture Toughness, 
Temperature Effect, Fractography

\section{Introduction}

Fiber reinforced polymer composites (FRPCs) are finding wide applications in primary structures of aircrafts, space crafts, ocean vehicles, automotive components as well as other cladding applications. These applications sometimes face a wide range of environmental exposure like low temperature, acidic water, high temperature, organic fuel, water, saline water, etc. [1]. Thus the understanding of fracture behavior and prediction of fracture toughness of FRPCs under different environmental exposure have assumed greater importance. The determination of stress intensity factor has become mandatory for structural applications. Previous research works have focused on the effect of higher temperature on fracture toughness of glass/carbon fibers reinforced epoxy composites. No study has been reported to determine the low temperature response of FRPCs with functional fillers. In this context, it is very important to understand the complete fracture behavior of FRPCs with fillers at cryogenic, room and high temperatures before used for end applications. In recent years, successful applications of advanced polymer matrix composites in structural components of aircraft have stimulated significant interest in the effects of environmental temperature on delamination behavior. The environmental temperature considerably affects the fracture toughness in thermo set matrix composites. There is a growing demand for FRPCs in lightweight primary structures as well. The strength and toughness of the fiber reinforced epoxy composite depends on the type, shape, aspect-ratio and surface modification of fiber [2]. Fiber/filler inclusion into polymer increases the fracture toughness [3]. A number of researchers carried out experiments to improve the fracture toughness of neat epoxy by the addition of organic and inorganic fillers viz., silica, sand particles, wood flake, and graphite [4] [5] [6] [7]. Srivastava et al. [8] studied the fracture behaviour of epoxy resin filled with FAC particles. They concluded that the modulus of elasticity, fracture surface energy and fracture toughness of epoxy resin can be improved by filling FAC. Shao et al. [9] indicated that the composite strength and fracture toughness are strongly dependent on the particle size, particle/matrix adhesion and particle loading. Past research works have also showed that by reinforcing different fibers like glass, carbon and aramid, the fracture toughness of epoxy matrix can be enhanced [10] [11] [12] [13]. In an attempt to enhance the fracture toughness of thermoset polymer composites, the simple approach is to add a lower Tg compound, such as rubber, soft thermoplastic polymer, diluents into the epoxy matrix [14]. By varying the proportions of hardener and resin and postcuring temperature on epoxy, Mostovoy and Ripling [15] found that the toughness of the epoxy either in bulk or bond form varied by a factor of approximately five. The environmental effects on thermoset polymer composite properties were also discussed in the literature [16] [17] [18] [19]. Nishijima et al. [16] reported that epoxy resins could have higher fracture toughness at the cryogenic temperature as compared to room 
temperature. Sung et al. [17] studied the fracture toughness and failure mechanisms of epoxy resin composites filled with silica particles, in the temperature range $-50^{\circ} \mathrm{C}$ to $80^{\circ} \mathrm{C}$. They concluded the significant effects of temperature and loading rate on fracture toughness, which showed a peak value at ambient temperature and decreases with increase in temperature. Yang et al. [18] have studied the fracture toughness of epoxy resin at cryogenic temperature by addition of carboxylic-nitrile-butadiene (CTBN) nano-rubber. The results showed that fracture toughness was higher at cryogenic temperature than that of room temperature. Masaya et al. [19] have investigated interlaminar fracture characterization of woven glass/epoxy composites at cryogenic temperature and concluded that the fracture toughness at cryogenic temperature seems to be higher than that at room temperature. Bang et al. [20] found that the thick adhesive joint had a reduced bonding strength at the cryogenic temperature, but the glass fiber reinforcement improved much the bonding strength and fracture toughness for thicker adhesive at the cryogenic temperature.

The effects of increasing temperature on fracture toughness of polymeric composites were also investigated by few researchers. Soon et al. [21] studied the temperature dependence of fracture toughness of silica/ epoxy composites at temperature range from $-148^{\circ} \mathrm{C}$ to $252^{\circ} \mathrm{C}$. They found deterioration of fracture toughness with increase in temperature. Magid et al. [22] studied the combined effects of load, moisture and temperature on the properties of E-glass/epoxy composites. For a short duration and submerged in distilled water the material exhibited an increase in strength, decrease in modulus, and increase in strain to failure. When the temperature was raised to $65^{\circ} \mathrm{C}$ and for longer duration, the strength was decreased by $18 \%$ and the modulus by $28 \%$. From the cited literature, it can be concluded that addition of micro/nanofillers and inclusion of fibers like glass and carbon into epoxy enhanced the fracture toughness at room temperature. However, at elevated temperature, almost all the researchers have found decrease in fracture toughness because of ductile behavior of the composite materials. At cryogenic temperature the fracture toughness was found to increase because of the increase in bonding strength. Mechanical properties glass fiber reinforced epoxy and their hybrid composites in terms of tensile, flexure and impact strength of have been widely studied in the past. However, to the best of author's knowledge, studies on flexural strength and fracture toughness of graphite/FAC filled glass fabric reinforced epoxy composites are not available in the literature. Hence, in this experimental work, the aim of our characterization is to develop micron-sized graphite and FAC particles in E-glass fabric reinforced epoxy (G-E) and fabricate novel hybrid epoxy composites with multi-phase and uniformly distributed. The incorporation of rigid FAC and lubricating graphite are supposed to further enhance the fracture toughness of G-E composite. Influences of graphite and FAC filler loadings on the flexural strength of G-E composites were evaluated under cryogenic, room and at high temperatures and discussed in detail. Further, the tests were also conducted to study the effect of these fillers on plane-strain fracture toughness of G-E hybrid epoxy composites under cryogenic, room and at high temperatures. The fracture and toughening mechanisms were also 
investigated by observing how the crack front interacts with the graphite and FAC in the hybrid epoxy composites through scanning electron microscopy (SEM). The experimental results showed that the flexural strength and fracture toughness of G-E composite with graphite/FAC fillers were superior to unfilled G-E composites and the optimum data were found in $10 \mathrm{Gr}+\mathrm{G}-\mathrm{E}$ hybrid composites. The difference in the effect of the type and filler loading is discussed with reference to fractographic observation results derived from SEM.

\section{Experimental Work}

\subsection{Raw Materials}

Raw materials used in this study include, epoxy resin and E-glass woven roving bidirectional fabric made by interweaving direct roving in plain weave pattern (360 gsm). Graphite is an inorganic material that has the potential to be used as lubricating filler in various polymer matrices and exist in several crystalline phases which all revert to the most stable hexagonal alpha phase at elevated temperatures. This phase is of particular interest for bearing and electrical insulator applications. The graphite powder selected for the present work has an average particle size in the range of $40-60 \mu \mathrm{m}$ and with $82 \%$ purity. Fly ash (FA), a finely divided powder generated in huge quantities during power generation in coal based power plants. It is essentially a mixture of ceramic materials such as: $\mathrm{SiO}_{2}, \mathrm{Fe}_{2} \mathrm{O}_{3}, \mathrm{Al}_{2} \mathrm{O}_{3}$ and $\mathrm{TiO}_{2}$. Composition/Chemical formula of FA are $\mathrm{SiO}_{2}$ (48.3\%), $\mathrm{Al}_{2} \mathrm{O}_{3}$ (20.2\%), $\mathrm{Fe}_{2} \mathrm{O}_{3}$ (6.4\%), $\mathrm{TiO}_{2}$ (1.9\%). The $\mathrm{FA}$ of particle size 45 - 65 $\mu \mathrm{m}$ was obtained from Pozocrete Minerals, Mumbai, India. The details of the materials used are listed in Table 1.

\subsection{Preparation of Graphite and Fly Ash Cenosphere by Silane Treatment}

For the preparation of silane treated graphite, it was carried out in absolute ethanol mixture. Firstly, $43 \mathrm{~g}$ graphite was added into $43 \mathrm{~mL}$ ethanol and vigorously stirred by a

Table 1. Details of the materials for the present work.

\begin{tabular}{lccl}
\hline \multicolumn{1}{c}{ Materials } & Designation & Density $\left(\mathrm{g} / \mathrm{cm}^{3}\right)$ & \multicolumn{1}{c}{ Supplier } \\
\hline Bisphenol-A epoxy resin (MY740) & E & 1.15 & \\
Anhydride type hardener & --- & --- & $\begin{array}{l}\text { Huntsman Advanced } \\
\text { Materials, USA }\end{array}$ \\
(HY918) Accelerator (DY062) & --- & --- & \\
E-glass woven roving fabric & G & & $\begin{array}{l}\text { M/S Madhu Glasstex Pvt. } \\
\text { Limited. Ahmedabad, India } \\
\text { Silane }\end{array}$ \\
Graphite & --- & --- & Sigma Aldrich, India \\
Fly ash cenosphere & Gr & 2.36 & Sigma Aldrich, India \\
\hline
\end{tabular}


vertical stirrer for $20 \mathrm{~min}$. Then, $2 \%$ organo-reactive silane coupling agent was mixed with the above mixture at $60^{\circ} \mathrm{C}$, and the reaction was processed for $2 \mathrm{~h}$ under stirring. The treated graphite was then dried at $100^{\circ} \mathrm{C}$ in an oven for about $3 \mathrm{~h}$ to allow complete evaporation of the ethanol. Similar procedure was followed to fly ash cenosphere particles for silane treatment.

\subsection{Manufacturing of Laminates}

All the composites were prepared by hand layup technique followed by compression moulding method. First, the graphite/FA filler particles were dried in an oven at $80^{\circ} \mathrm{C}$ for $24 \mathrm{~h}$. The epoxy resin was preheated in the same way, to lower the viscosity and to enable a better wetting of the filler particles. After incorporating the required amount of silane treated filler particles (graphite/FA) into the epoxy resin, the mixture was then vibrated for $30 \mathrm{~min}$ by placing it into ultrasound vibrator. The hardener ( $85 \mathrm{wt} \%)$, and accelerator ( $2 \mathrm{wt} \%$ each) were added to the filler-resin mix and vibrated the mixture for $10 \mathrm{~min}$. Eight/thirty two layers of glass fabrics ( $55 \pm 1$ by weight) were used to obtain $3 / 10 \mathrm{~mm}$ thick laminates. The glass-epoxy composite was prepared by hand lay-up procedure followed by compression moulding. The stacking procedure consists of placing the fabric one above the other with the resin mix well spread between the fabrics. A porous Teflon film is placed on the completed stack. To ensure uniform thickness of the sample a spacer of size $10 / 3 \mathrm{~mm}$ was used. The mould plates have a release agent smeared on them. The whole assembly is pressed in a hydraulic press $(0.5 \mathrm{MPa})$ and allowed to cure for $24 \mathrm{~h}$. The laminate so prepared has a size $300 \mathrm{~mm} \times 300 \mathrm{~mm} \times 10 / 3$ $\mathrm{mm}$. To prepare the laminates of particulate filled (G-E) composites, selected fillers (graphite and FA; average particle size: $25 \mu \mathrm{m}$ ) are mixed using high shear mixer for uniform dispersion in the known quantity of epoxy resin. Table 2 summarizes the details of the composites fabricated and investigated in this work.

\subsection{Three-Point Bend Test}

The flexural strength of the developed G-E and their hybrid composites were determined by placing the samples under flexural loading using a three-point loading fixture. The flexural tests were performed on universal testing machine (UTM, Make: Kalpak-100 kN) in accordance to ASTM D790-10. A $10 \mathrm{kN}$ load cell was used and load

Table 2. Compositional details with sample codes of composite laminates fabricated.

\begin{tabular}{lcccc}
\hline \multicolumn{1}{c}{ Composition } & Specimen Code & Glass fiber wt\% & Epoxy wt\% & Filler wt\% \\
\hline Glass-Epoxy & G-E & 55 & 45 & - \\
Graphite filled Glass-Epoxy & $5 \mathrm{Gr}+\mathrm{G}-\mathrm{E}$ & 55 & 40 & 5 \\
Graphite filled Glass-Epoxy & $10 \mathrm{Gr}+\mathrm{G}-\mathrm{E}$ & 55 & 35 & 10 \\
FAC filled Glass-Epoxy & 5FAC+G-E & 55 & 40 & 5 \\
FAC filled Glass-Epoxy & 10FAC+G-E & 55 & 35 & 10 \\
\hline
\end{tabular}


versus deflection data were collected for all measurements. The loading was of displacement-controlled type. During flexural test, a span length of $64 \mathrm{~mm}$ was chosen for $3 \mathrm{~mm}$ thick sample, and the tests were carried at cross-speed of $0.5 \mathrm{~mm} / \mathrm{min}$. The flexural strength $\left(\sigma_{f}\right)$ evaluation was based on the Equation:

$$
\sigma_{f}=\frac{3 P L}{2 b t^{2}}
$$

where $P=$ rupture load in $\mathrm{N}, L=$ effective span in $\mathrm{mm}, b=$ width of specimen in $\mathrm{mm}$, and $t=$ thickness of specimen in $\mathrm{mm}$.

\subsection{Fracture Toughness Testing}

Mode-I fracture toughness $\left(\mathrm{K}_{\mathrm{IC}}\right)$ testing of single edge notch bend (SENB) specimens was carried out on a universal testing machine (Make: Kalpak, Pune, $100 \mathrm{kN}$ ) according to ASTM D 5045-99. An initial pre-crack which is critical to fracture toughness testing, was introduced to each SENB sample by a razor blade-tapping method [23]. The specimen was loaded in a standard three-point bend fixture of as shown in Figure 1 at room temperature testing. The tests were conducted on monotonic loading and applied at a constant displacement rate of $10 \mathrm{~mm} / \mathrm{min}$, and a minimum of four specimens were tested for each composite specimen. The mode-I stress intensity factor $\left(\mathrm{K}_{\mathrm{IC}}\right)$ at the point fracture initiation was determined using the equations as per the ASTM D 504599. Complete details of the testing procedure and calculation of fracture toughness are given elsewhere [24] (Figure 1). Universal Testing Machine showing the sample position at room temperature. The tests were also carried out at $100^{\circ} \mathrm{C}$ and the arrangement as shown in Figure 2. The SENB specimen was fixed in the environmental chamber and heated the chamber up to $100^{\circ} \mathrm{C}$ after attaining the required temperature the tests were conducted.

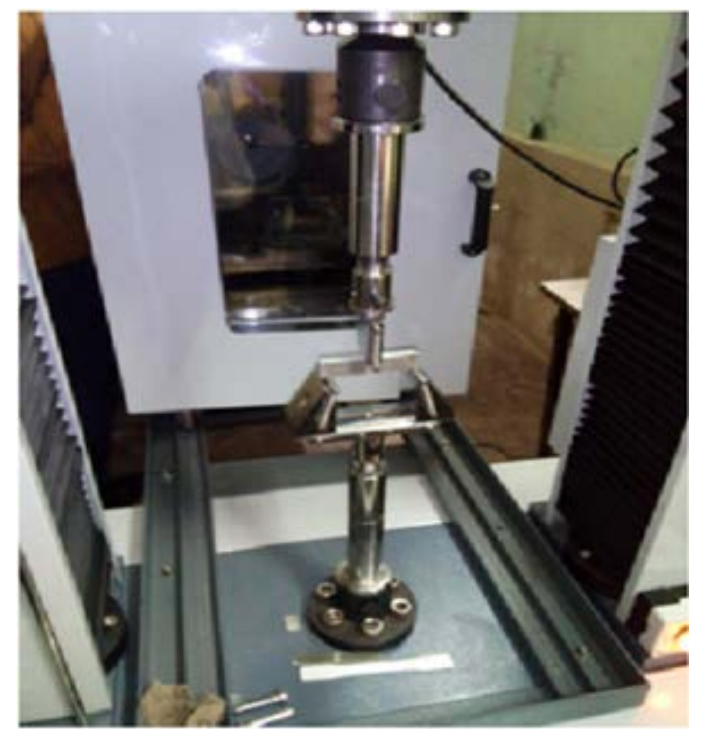

Figure 1. Universal testing machine showing the sample position at room temperature. 
Figure 3 shows the cryogenic chamber used for testing of SENB specimen in the cryo-environment. The chamber is connected to liquid nitrogen through rubber tube from the tank of 50 ltr capacity. To set the chamber temperature at $-30^{\circ} \mathrm{C}$, liquid nitrogen is constantly supplied to the chamber to compensate for the liquid nitrogen lost due to boiling. The specimen was kept in a chamber to attain the required temperature before conducting the test.

\section{Results and Discussion}

\subsection{Effect of Type and Filler Loading on Flexural Strength}

It is well known that the type of fiber and filler content are mainly responsible for improving the strength of the composite. Therefore variation in strength of the composite with various filler loading is obvious. The variation in flexural strength of unfilled G-E and particulate filled (graphite and FAC) G-E hybrid composites with 5 and $10 \mathrm{wt} \%$ filler loading at cryogenic, room and high temperature are represented in Figure 4(a) and Figure 4(b) respectively. It is well known that the type of fiber and filler content are mainly responsible for improving the strength of the composite. Therefore variation in strength of the composite with various filler loading is obvious. The variation in flexural strength of unfilled G-E and particulate filled (graphite and FAC) G-E hybrid composites with 5 and $10 \mathrm{wt} \%$ filler loading at cryogenic, room and high temperature are
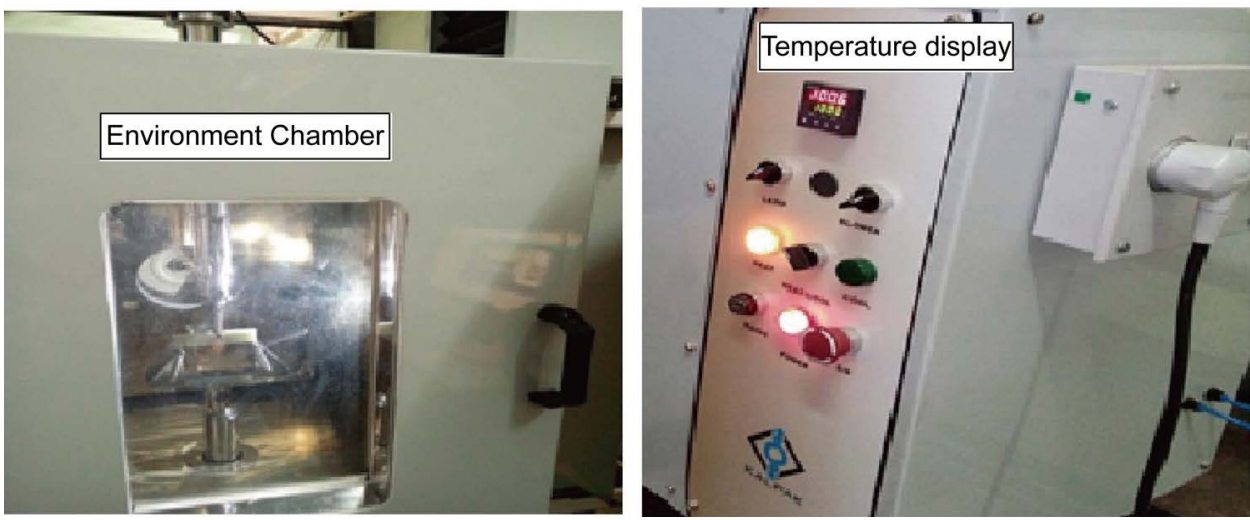

Figure 2. Universal testing machine showing the sample position at elevated temperature.
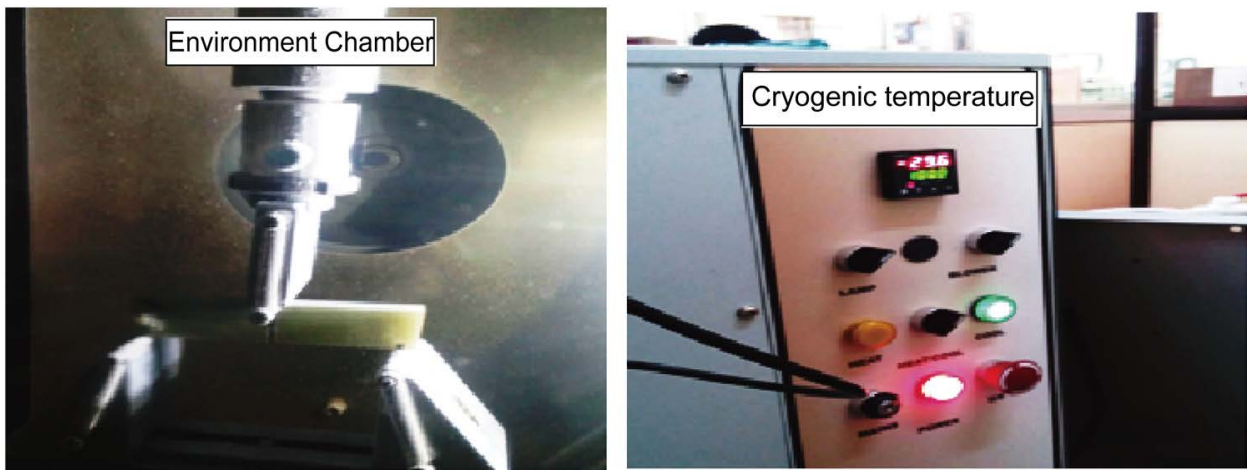

Figure 3. Universal testing machine showing the sample position at cryogenic temperature. 
represented in Figure 4(a) and Figure 4(b) respectively.

\subsubsection{Flexural Strength of Hybrid Composites at Room Temperature}

The flexural strength of G-E and their composites at room temperature (RT) are shown in Figure 4(a) and Figure 4(b). The figure clearly indicates that $10 \mathrm{Gr}+\mathrm{G}-\mathrm{E}$ has the highest flexural strength, followed by $10 \mathrm{FAC}+\mathrm{G}-\mathrm{E}$ composite at room temperature. The

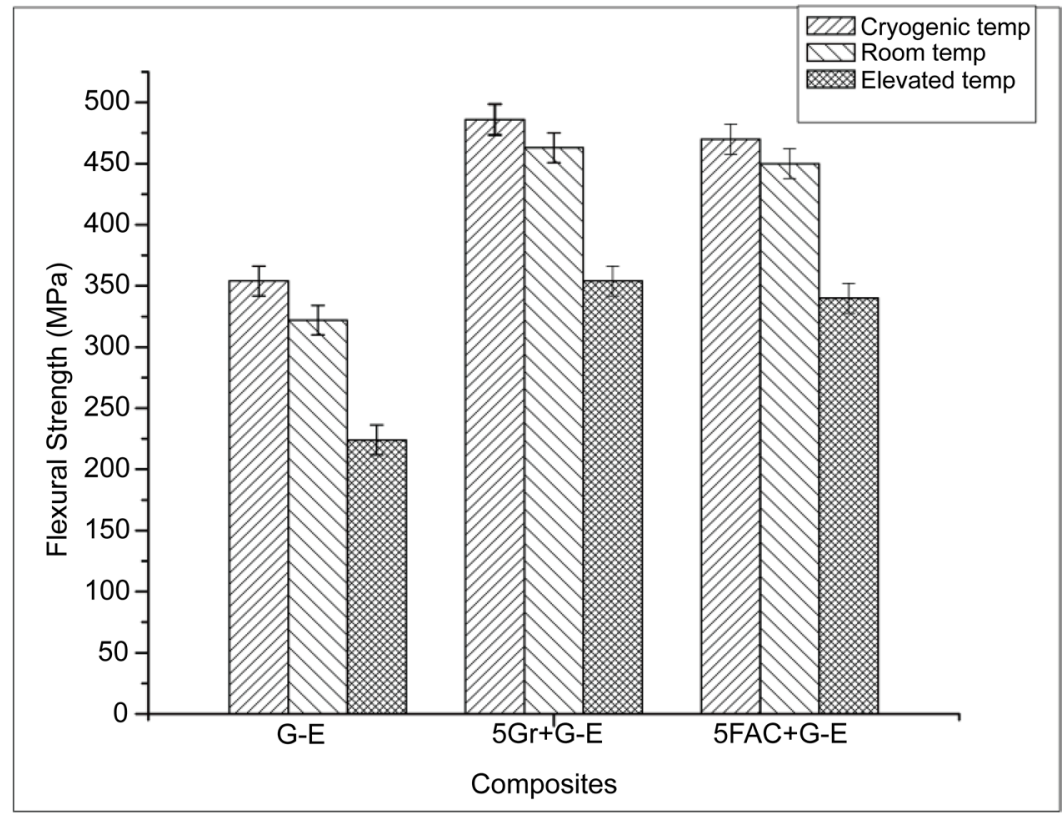

(a)

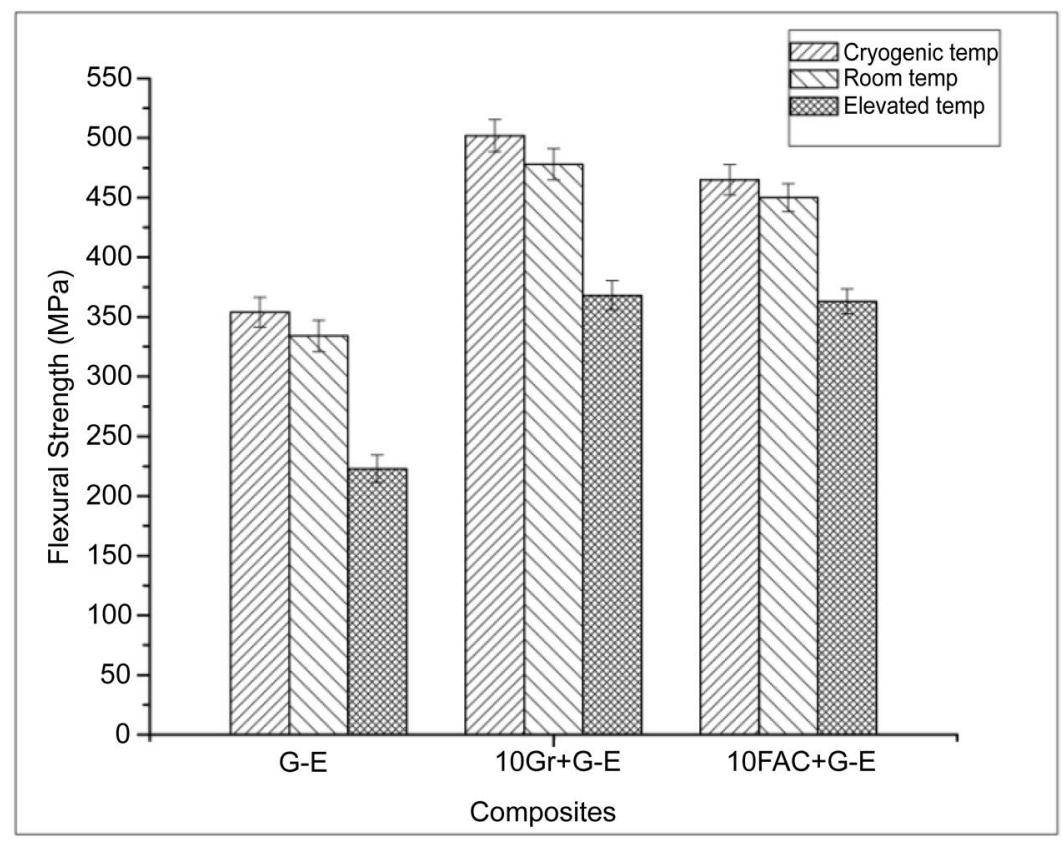

(b)

Figure 4. (a) Flexural strength of G-E and 5 wt\% particulate filled G-E hybrid composites. (b) Flexural strength of G-E and $10 \mathrm{wt} \%$ particulate filled G-E hybrid composites. 
incorporation of graphite and FAC fillers resulted in improvement of the flexural strength, which increased by $43 \%$ and $37.7 \%$ for $10 \mathrm{Gr}+\mathrm{G}-\mathrm{E}$ and $10 \mathrm{FAC}+\mathrm{G}-\mathrm{E}$ hybrid composites. Note that $5 \mathrm{Gr}+\mathrm{G}-\mathrm{E}$ was incorporated with graphite and in this study, a high shear mixer was used to mix the epoxy and fillers with low shear force, which to some extent maintained the layered and network structures of graphite particles in the G-E composite. Also, low viscosity allowed the epoxy resins and the curing agent to penetrate into the gallery and fill the micro-pores of the graphite particles. Also, the pressure applied during compression moulding of composite led to the reduction in the voids and defects. Furthermore, synergistic combination of graphite and high strength bi-directional glass fabric allowed substantial reduction in the filler loading to attain high flexural strength. An increased surface area by the incorporation of graphite ensures better wetability of the fibers by the matrix leading to an efficient load transfer between the two. The flexural strength of G-E with FAC is also higher than the unfilled G-E composite. This is probably due to the disorder of interfacial adhesion between FAC particles and epoxy in the presence of glass fabric. However, in graphite filled G-E hybrid composite, small amounts of reactive functional groups such as carboxyl and epoxide groups on the surface of graphite might have readily reacted with the epoxy resin and developed strong interfacial adhesion between the graphite particles and epoxy matrix. This in turn resulted in high flexural strength for graphite filled G-E composites.

\subsubsection{Flexural Strength of Hybrid Composites at an Elevated Temperature} The flexural strength of G-E and their composites at elevated temperature (ET) are shown in Figure 4(a) and Figure 4(b). The figure clearly indicates that for all composites, the flexural strength decreases considerably at an elevated temperature of $100^{\circ} \mathrm{C}$. The strength loss computed in the unfilled G-E specimens is, again, higher than the loss reported for graphite and FAC filled G-E hybrid composites. At elevated temperature, G-E with $10 \mathrm{wt} \%$ graphite $10 \mathrm{Gr}-\mathrm{G}-\mathrm{E}$ has the highest flexural strength (368 MPa), followed by 10FAC-G-E composite (363 MPa). The incorporation of graphite and FAC fillers resulted in decrease of the flexural strength, which decreased by $23 \%$ and $21 \%$ for $10 \mathrm{Gr}+\mathrm{G}-\mathrm{E}$ and 10FAC+G-E hybrid composites. The effect of ET testing of epoxy polymer mortar composites was reported by Joao et al. [25]. They pointed out that the increasing the test temperature, significantly decreased the flexural strength of epoxy polymer mortar composites. In the present work, upon increasing the test temperature to $\left(100^{\circ} \mathrm{C}\right)$, the brittle performance is reported and remarkable decrease in the flexural strength is observed. Furthermore, for unfilled G-E specimens become more brittle at $100^{\circ} \mathrm{C}$ and a higher loss in flexural strength of about $33 \%$ was found. Particulate filled hybrid composite Specimens tested at $\left(100^{\circ} \mathrm{C}\right)$ show a marginal loss in the strength as shown in Figure 4 and for these hybrid composite specimens, the loss of load bearing capacity decreased at ET. This behaviour is associated with a progressive loss of composite material stiffness, turning the brittle characteristics of the epoxy composites into ductility. The change in the particulate filled G-E behaviour is related to the heat distortion temperature (HDT) values of the epoxy resin used as matrix material. 


\subsubsection{Flexural Strength of Hybrid Composites at Cryogenic Temperature}

The flexural strength of G-E and their composites at cryogenic temperature (CT) are shown in Figure 4(a) and Figure 4(b). Flexural strength shows a higher value at cryogenic temperature that at room temperature or elevated temperature for all composite samples. In cryogenic temperature epoxy resins are generally brittle and hard and more bonding between the fillers and matrix therefore load bearing capacity is increased at this environment. The specimens observed at this environment have more stress than the strain, higher flexural strength at cryogenic environment using various modifiers such graphite and FAC fillers. At cryogenic temperature $4 \%$ of flexural strength was improved in G-E composites and 5\% increase for graphite filled G-E composites and $4 \%$ increase in case of FAC filled G-E composites. Similar observations are also found in $10 \mathrm{wt} \%$ filled G-E hybrid composites. Gong et al. [26] and Kim et al. [27] have reported that the flexural strength and modulus for a UD glass-epoxy composite increased at cryogenic temperature. As a result, it was speculated that the brittleness of the fibers had a major influence on the strength increase of composites at low temperature. The flexural strength data shown in Figure 4(a) and Figure 4(b) clearly depicts that $10 \mathrm{Gr}+\mathrm{G}-\mathrm{E}$ has the highest flexural strength (502 MPa), followed by $10 \mathrm{FAC}+\mathrm{G}-\mathrm{E}$ composite $(485 \mathrm{MPa})$ at $\mathrm{CT}$.

\subsection{Effect of Type and Filler Loading on Fracture Toughness}

The toughness or resistance to crack growth of a material is governed by the energy absorbed as the crack extend. For a brittle material, the energy is primarily just that of rupturing in chemical bond along the crack plane, but in tougher material like epoxy resins, bond rupture plays a relatively small role in resisting crack growth, with by far the largest fraction of the fracture energy being associated with plastic flow near the crack tip. Fracture toughness of polymer based composites depends on fiber, filler and matrix properties as well as fabrication method. Many attempts have been made to improve the structural properties of two-phase polymer composite by incorporating inorganic fillers. This improves the hardness and stiffness of hybrid composites because of strong bonding between the particulate and the matrix and larger surface area covered by the filler [3] [4] [5]. Similar observations were also reported in the literature [23] [28] [29]. The fracture toughness of G-E, graphite and FAC filled G-E hybrid composites fabricated by compression moulding is studied. Fracture toughness results for these composites are shown in Figures 5-8. It can be seen from the figures that the fracture toughness are dependent on testing temperature.

\subsubsection{Fracture Toughness of Hybrid Composites at Room Temperature}

The load-displacement curves for particulate filled G-E hybrid composites are shown in Figure 5. It is seen that the load-displacement curves are initially linear, which becomes progressively non-linear and drops rapidly with increase in displacement. Further, at room temperature the highest and lowest peak load were found at $10 \mathrm{wt} \%$ graphite filled and unfilled G-E composites respectively. The load bearing capacity for unfilled G-E sample is decreased because of crack was developed in the specimen and no further 


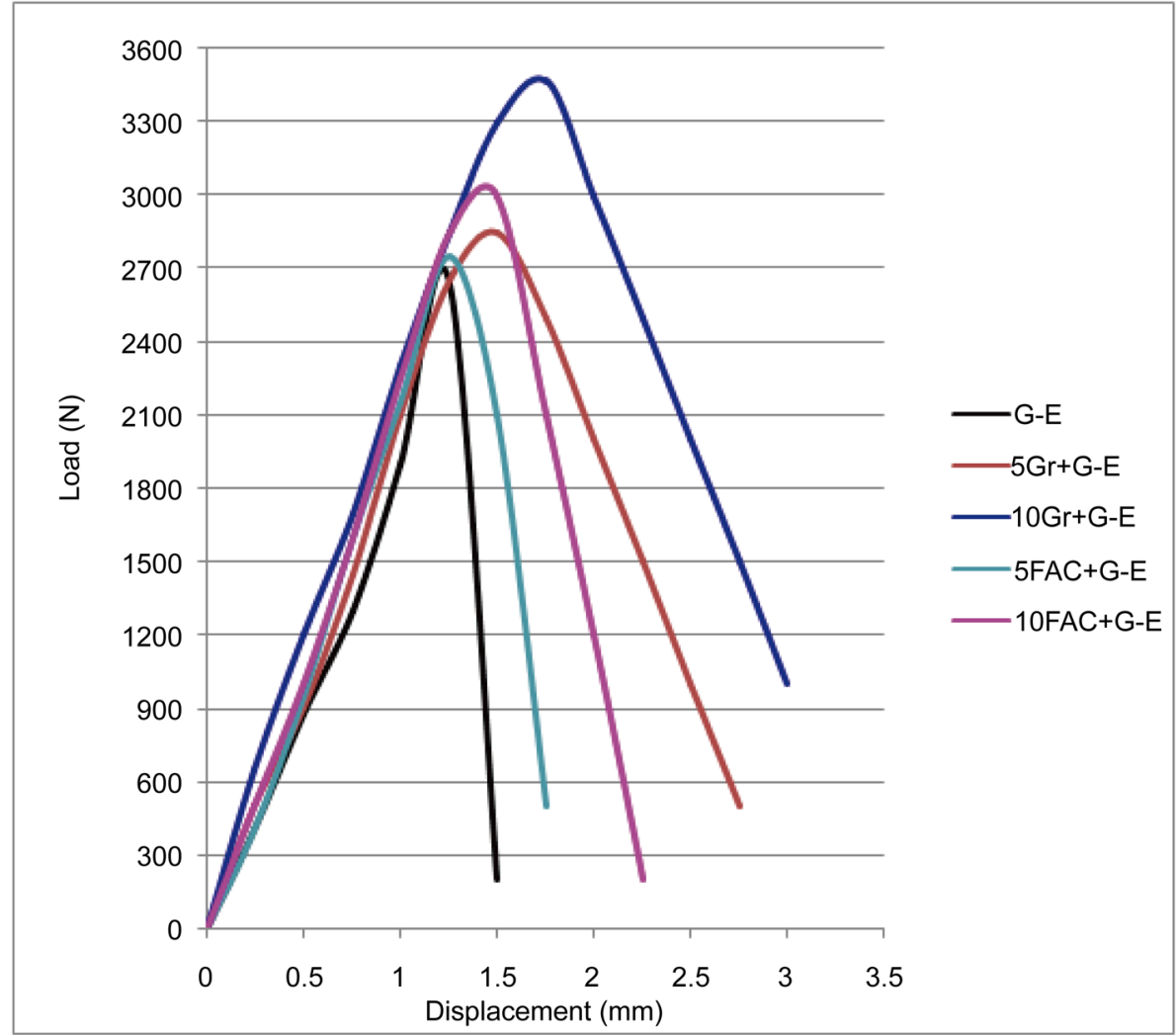

Figure 5. Load-displacement curves of particulate filled values of composites at room temperature.

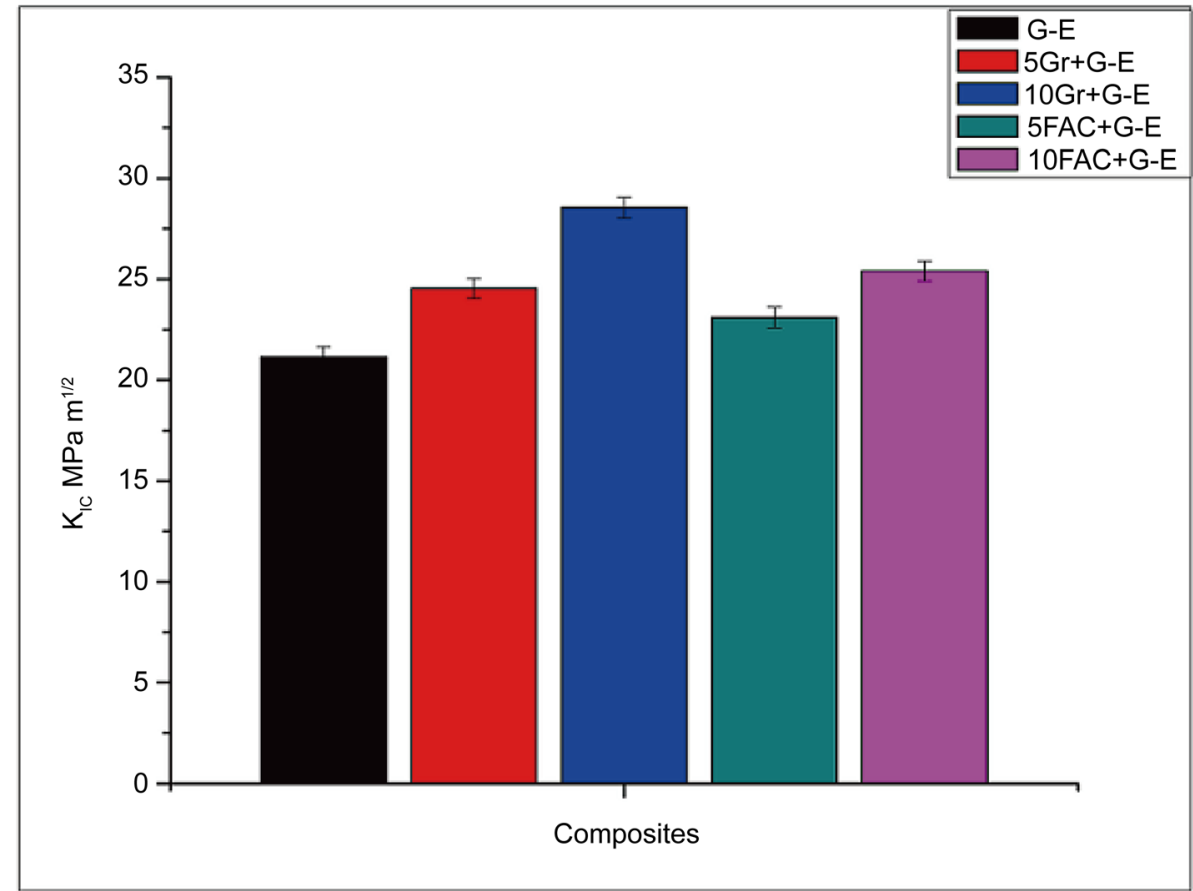

Figure 6. Fracture toughness of unfilled and particulate filled G-E hybrid composites at room temperature. 


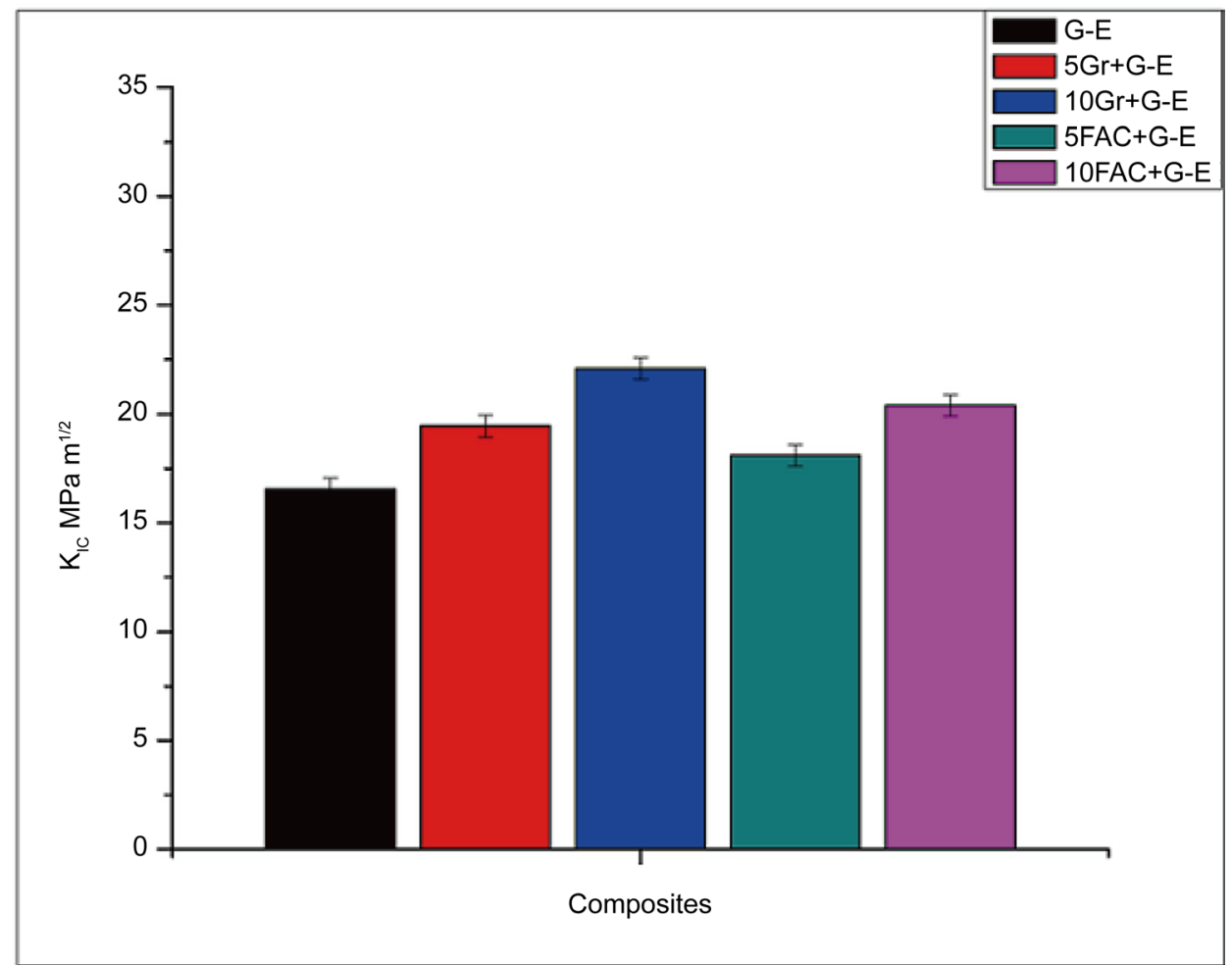

Figure 7. Fracture toughness of unfilled and particulate filled G-E hybrid composites at elevated temperature.

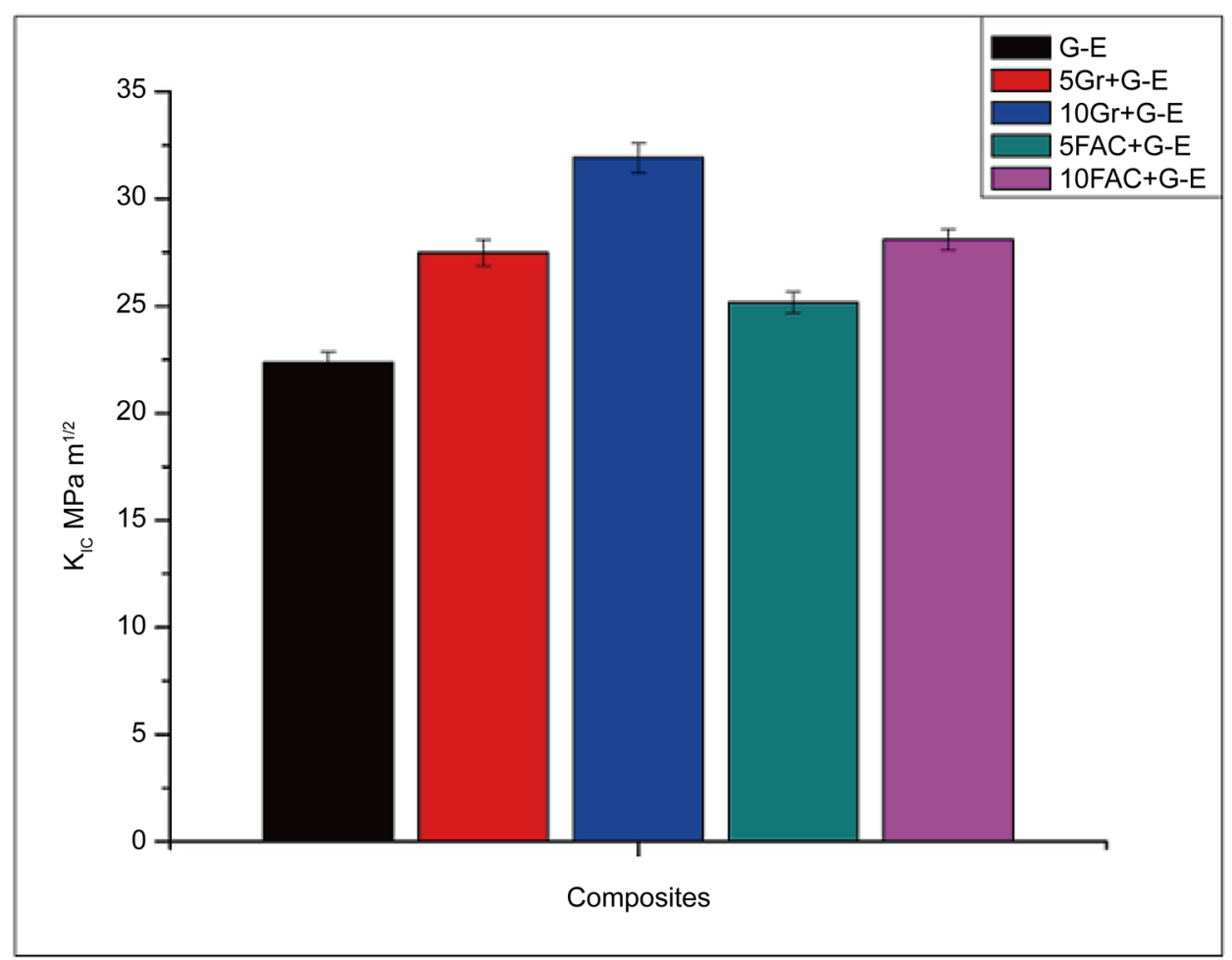

Figure 8. Fracture toughness of unfilled and particulate filled G-E hybrid composites at cryogenic temperature. 
load is required and material becomes ductile i.e. the load-deflection curve was nonlinear after brittle failure.

The fracture toughness $\left(\mathrm{K}_{\mathrm{IC}}\right)$ at room temperature for unfilled and particulate filled G-E hybrid composites is presented in Figure 6. It is clear that $\mathrm{K}_{\mathrm{IC}}$ of FAC filled G-E hybrid composites increase marginally up to $5 \mathrm{wt} \%$ and augment with increasing filler loading (10 wt\%). However, the unfilled two-phase G-E composite shows low fracture toughness of $21.15 \mathrm{MPa} \mathrm{m}^{1 / 2}$ and the addition graphite significantly increased the $\mathrm{K}_{\mathrm{IC}}$ to 28.25 MPa $\mathrm{m}^{1 / 2}$ which yielded about $33 \%$ improvement. This indicates filler loading increased the load carrying capacity of G-E composite. Similar observations were also reported by other researchers [3] [4] [5] [6] [7].

In general, the degree of translation of matrix toughness into fracture toughness of composite depends on the matrix toughness. In the present work, the epoxy is a tougher matrix (0.5 - $3 \mathrm{MPa} \mathrm{m}^{1 / 2}$ ) [30] and brittle and reinforced with E-glass fabric enhanced the $\mathrm{K}_{\mathrm{IC}}$. Furthermore, with an increase in graphite filler concentration the $\mathrm{K}_{\mathrm{IC}}$ improved and the data generated in this study on G-E with FAC filled hybrid composites show similar relationship with lower fracture toughness values. Thus, in case of FAC filled G-E hybrid composites, the results suggest that resin fracture toughness is not fully transferred to the composite. In addition, there are several other toughening mechanisms that are present in the multiphase composite but are absent in two-phase composite. For example, in a three-phase composite, if the interfacial shear strength is stronger than the matrix strength, the crack will have a preference to go through the weaker resin rather than breaking the strong fibers and fillers. However, because of combination of fibers and fillers and very small thickness between the plies, there is no plane containing only resin $\mathrm{n}$ or the filler-resin mix. In such a situation the crack must always go around fibers creating a much larger fracture surface area. Moreover, the resistance to crack growth will be increased by the uneven fibers and poor distribution of FAC particles that may lie in the path of the advancing crack. All these mechanisms add to the composite $\mathrm{K}_{\mathrm{IC}}$. It has been suggested that the contribution of each of these toughening mechanisms to the composite $\mathrm{K}_{\mathrm{IC}}$ will be highest for minimum possible thickness of the resin-rich region. Bhandakkar et al. [31] studied the interlaminar fracture toughness of glass-epoxy filled FAC laminates before and after exposure to aqueous fog using a salt fog chamber at $45^{\circ} \mathrm{C}$. They reported improvement in interlaminar fracture toughness of FAC filled glass-epoxy in unexposed and exposure to aqueous fog conditions.

\subsubsection{Fracture Toughness of Hybrid Composites at Elevated Temperature}

The load carrying capacity at an elevated temperature for all composite specimens has been decreased. The main problem associated with the polymers, arises from the viscoelastic properties of the polymer, which results in creep and high sensitivity to the temperature [32]. It is noticed that the specimen with $10 \mathrm{wt} \%$ graphite filler had the highest peak load. The specimen with $10 \mathrm{wt} \%$ FAC performs also better at an elevated temperature and the least being the specimen with unfilled G-E composite. The matrix behaviour has been changed due to prolong exposure to elevated temperature and has 
ablated a fraction of matrix from the specimen. In addition, under high temperature, the dissimilarity in the thermal coefficient behaviour of matrix and fiber causes different expansion and contraction characteristics, resulting in micro cracks, debonding and delamination at the interface region. Ashcroft et al. [33] have concluded that the temperature influenced the mode of fracture which progressed from stable, brittle fracture at low temperatures to slip-stick fracture at room temperature and finally to stable ductile behaviour at elevated temperatures.

The fracture toughness $\left(\mathrm{K}_{\mathrm{IC}}\right)$ at elevated temperature for unfilled and particulate filled G-E hybrid composites is presented in Figure 7. It has resulted in the lower value of $\mathrm{K}_{\mathrm{IC}}$ showed in all the composite specimens at elevated temperature than at the room temperature. This observation therefore, suggests a strong influence of environment on the $\mathrm{K}_{\mathrm{IC}}$ of G-E composites.

\subsubsection{Fracture Toughness of Hybrid Composites at Cryogenic Temperature}

The fracture toughness of polymers will generally be increased when temperature decreases from room temperature to cryogenic temperature. The brittleness of the polymers limits their applications in cryogenic environments. Hence, cryogenic fracture toughness is a very important parameter for polymer and their composites used in extremely low temperature environments. Some thermoset polymers (epoxy resins) are often modified using various modifiers. In the present work, we focused on the effect of two types of fillers viz., graphite and FAC on fracture toughness of G-E composites. The cryogenic $\mathrm{K}_{\mathrm{IC}}$ of graphite/FAC filled G-E hybrid composites is investigated as a function of filler loading. It was found that the fracture toughness enhancement obtained at cryogenic temperature. Kalarikkal et al. [34] have reported the effect of cryogenic temperature on $\mathrm{K}_{\mathrm{IC}}$ of graphite/epoxy composites the woven composite specimens showed the decreased in KIC. Composite specimens deteriorate significantly at cryogenic temperature because of development of thermal stress in the laminates and formation micro cracks in the laminates at low temperature, which leads to overall degradation of the material as well as embrittlement of the matrix.

The load carrying capacity of G-E and its hybrid composites at cryogenic temperature increases with increase in filler loading. The specimen with $10 \mathrm{wt} \%$ graphite filler had the highest peak load. The specimen with $5 \mathrm{wt} \%$ graphite performs remarkably better at cryogenic temperature as it shows characteristics as good as with $10 \mathrm{wt} \% \mathrm{FAC}$ and the least being $5 \mathrm{wt} \%$ of FAC. Nishijima et al. [16] reported that epoxy resin could have higher $\mathrm{K}_{\mathrm{IC}}$ at the cryogenic temperature than at room temperature. Indeed, $\mathrm{K}_{\mathrm{IC}}$ of the epoxy composites at the cryogenic temperature was higher than at room temperature. Figure 8 shows that 5.7\% fracture toughness increased in the G-E specimen, 13\% increased in the $10 \mathrm{wt} \%$ of graphite specimen and $10 \%$ increased in the $10 \mathrm{wt} \% \mathrm{FAC}$ filled G-E composites at cryogenic temperature than at room temperature. The effect of moisture was reported by Marom et al. [35] the short-term effect of water is to increase the $\mathrm{K}_{\mathrm{IC}}$, while in long run the toughness deteriorates. Shen et al. [36] [37] reported that laminates the ultimate tensile strength and elastic moduli decreased with increasing moisture content. The decreased might as $50 \%-90 \%$. When moisture diffuses into 
composites, it degrades the fiber-matrix interfacial bonding. Srivastava et al. [38] studied the moisture effect on $\mathrm{K}_{\mathrm{IC}}$ of particles filled quasi-isotropic glass-fiber reinforced polyester resin composites. They concluded that $\mathrm{K}_{\mathrm{IC}}$ of composites increased with increase in moisture uptake. Choi and Shankar [39] have concluded that $\mathrm{K}_{\mathrm{IC}}$ does not change significantly at cryogenic temperatures, but the thermal stresses play a most important role in fracture and initiation of delaminations from transverse cracks. Strictly speaking, the fracture parameters should be independent of the testing geometry and sample dimensions. However, $\mathrm{K}_{\mathrm{IC}}$ is one of the mechanical characteristics that have more difficulty in its determination and analysis, as well as there are numerous factors like temperature, strain rate, sample dimensions and testing geometry involved.

\subsection{Morphology Studies}

Figures 9-11 show the SEM micrographs of SENB fracture surface of the G-E, G-E with $10 \mathrm{wt} \%$ graphite and G-E with $10 \mathrm{wt} \%$ FAC filled G-E hybrid composites, respectively. From Figure 9(a), lower magnified image, illustrates the fractured surface of unfilled G-E composite showing the ' $U$ ' shaped crack path with matrix layer delaminated from the fiber surface and bunch of broken fibers in the length direction. Figure 9(b), magnified view depicts the associated fracture morphology of a bi-directional glass fabric reinforced epoxy composite during mode-I fracture toughness testing. Under mode-I (opening) loading, toughness is controlled by processes such as cohesive fracture of the epoxy matrix and fiber bridging (weft-direction). Fracture initiates as cracks at the fiber-matrix interface which then extend into the matrix between the fibers; the path of these cracks is approximately coincident with specimen width (W). From SEM micrograph shown in Figure 9(b), it is evident that fibers have failed in tension. Further, the individual fiber fracture show radial patterns, inclined fracture and partly failed i.e., chip-off from the fiber surface on the fiber ends. However, the warp fibers are disoriented and delamination of fibers from the matrix during fracture toughness testing can be seen from the SEM micrographs.
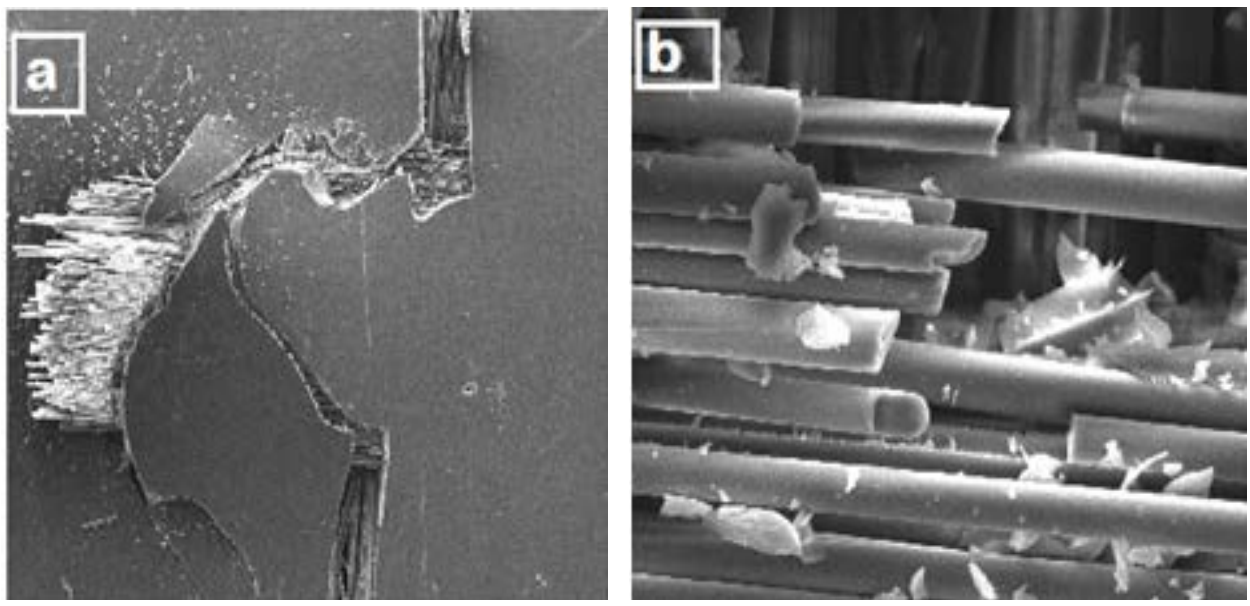

Figure 9. SEM micrographs of unfilled G-E fractured SENB specimen: (a) Lower magnification 50×; (b) Higher magnification 1500×. 

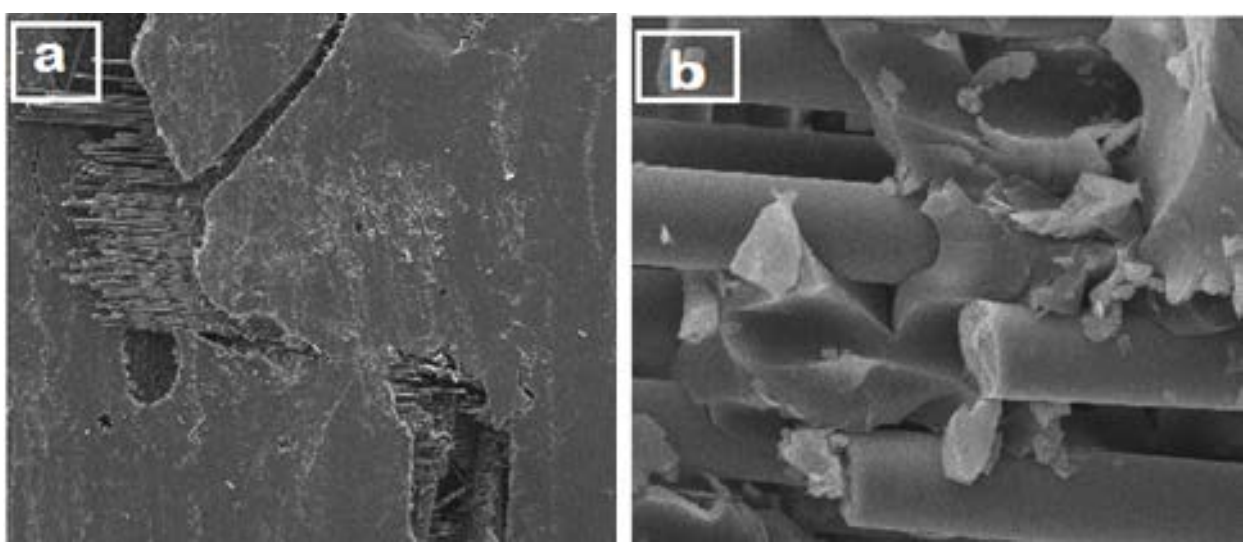

Figure 10. SEM micrographs of graphite filled G-E fractured SENB specimen: (a) Lower magnification 50×; (b) Higher magnification 1500×.
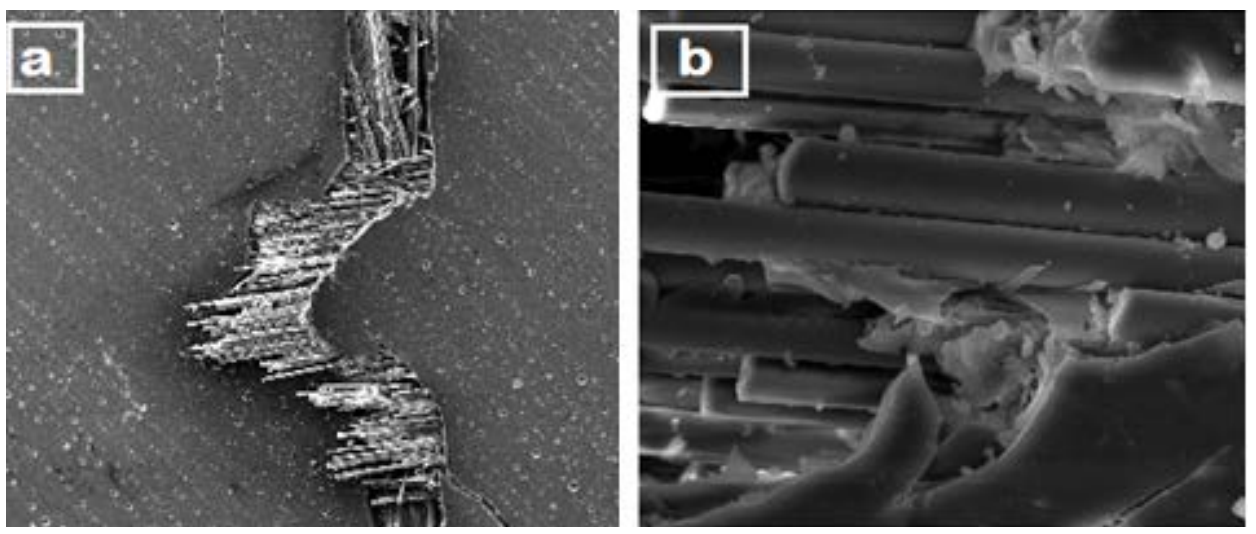

Figure 11. SEM micrographs of FAC filled G-E fractured SENB specimen: (a) Lower magnification 50×; (b) Higher magnification 1500×.

Figure 10 shows the fractured surface of $10 \mathrm{wt} \%$ graphite filled G-E hybrid composite. The fracture toughness of this composite was stronger than that of the unfilled G-E composite because some of stress was effectively transferred from the epoxy matrix to the reinforcements (fiber + filler). Further, it is revealed that the crack path is similar to that of unfilled G-E composite. Compared to the unfilled G-E, the fracture surface of the graphite filled G-E composites showed a much rougher fracture surface (Figure $10(a))$. The very rough surface is due to the presence of graphite particles, which makes the fracture path circuitous. This confirms a higher $\mathrm{K}_{\mathrm{IC}}$ value for $\mathrm{G}-\mathrm{E}$ composite with 10 wt $\%$ graphite compared to the unfilled G-E and FAC filled G-E composites. It was concluded that the inclusion of graphite into G-E composites has led to an increase in $\mathrm{K}_{\mathrm{IC}}$. The toughening mechanism in the graphite filled G-E composite may be attributed to the stress disturbance caused by the graphite particles. These graphite particles acted as obstacles, causing the crack to take a more circuitous part, manifesting a roundabout crack trajectory.

Figure 11 shows the fractured surface of $10 \mathrm{wt} \%$ FAC filled G-E hybrid composite. The fracture toughness of this composite was higher than that of the unfilled G-E compo- 
site because some of stress was transferred from the epoxy matrix to the reinforcements (fiber + filler). Further, it is revealed that the crack path is more or less similar to that of graphite filled G-E composite. It is also seen that the FAC filled G-E composite samples have a rougher surface than that of unfilled G-E specimen (Figure 11(a)). From SEM micrograph shown in Figure 11(b), it is evident that fibers have failed in tension. Further, the individual fiber fracture show radial patterns on the fiber ends, few FAC particles adhered to the fiber surface and good bonding between the fiber and epoxy matrix. The fracture surface observation coincides with the results of $\mathrm{K}_{\mathrm{IC}}$ of specimens. This indicates that the addition of FAC particles into G-E composite creates an increased fracture surface due to crack deflection, which led to the enhancement of $\mathrm{K}_{\mathrm{IC}}$.

\subsection{Conclusions}

In this paper, we prepared high performance graphite and FAC filled G-E hybrid composites with good flexural strength and fracture toughness. By liquid epoxy, hot curing, low viscosity (Huntsman Advanced Materials, USA), impregnating resin with reactive diluents ensured outstanding dispersity and good compatibility in the polymer matrix. The hybrid composites showed a high reinforcing efficiency, which attributed to the high strength glass fiber and special two dimensional morphology of graphite and functionalized surface of FAC providing well dispersion and large contact area in matrix. The main findings are: a) graphite and FAC particles improve flexural strength and mode-I plane-strain fracture toughness of G-E composite with increasing filler loading; b) graphite filler enhances the flexural strength and fracture toughness of G-E composite more significantly; c) hybridization of $10 \mathrm{wt} \%$ graphite in G-E can achieve maximum flexural strength and toughness; and d) fiber bridging, fiber pull-out, fiber breakage, delamination and matrix cracking are the major toughness contributors for graphite and FAC filled G-E hybrid composites. The graphite filled (10 wt.\%) G-E hybrid composite exhibit around 23\% improvement in the flexural strength and $27 \%$ improvement in plane-strain fracture toughness. It has been clearly demonstrated that the G-E composite with epoxy modified by both graphite and FAC can lead to great enhancements in $\mathrm{K}_{\mathrm{IC}}$. Further, enhancement in $\mathrm{K}_{\mathrm{IC}}$ is more pronounced in graphite filled G-E composites. In short, we endow with a promising approach to prepare graphite filled G-E hybrid composites with enhanced $\mathrm{K}_{\mathrm{IC}}$.

\section{Acknowledgements}

The authors acknowledge on the financial support extended from Technical Education Quality Improvement Programme (TEQIP-Phase II), MHRD, Government of India. Authors also, express their gratitude to the Principal and the Board of Management, The National Institute of Engineering, Mysuru, India for the support and encouragement for publication of this work.

\section{References}

[1] Masud, A.K., Zaman, A.K. and Abdallah, K. (2007) Effect of Environment on Fracture 
Toughness of Glass Fiber/Polymer Composites. Journal of Mechanical Engineering, 38, 3844.

[2] Lubin, G. (1992) Hand Book of Composites. Van Nostrand Reinhold, New York.

[3] Young, R.J. and Beaumount, P.W.R. (1997) Failure of Brittle Polymers by Slow Crack Growth: Part 3 Effect of Composition upon Fracture of Silica Particle-Filled Epoxy Resin Composites. Journal of Material Science, 12, 684-692.

http://link.springer.com/article/10.1007/BF00548158 http://dx.doi.org/10.1007/BF00548158

[4] Moloney, A.C. and Kausch, H.H. (1983) The Fracture of Particulate-Filled Epoxide Resins: Part 1. Journal of Material Science, 18, 208-216. http://link.springer.com/journal/10853 http://dx.doi.org/10.1007/bf00543827

[5] Amar, G.C. (1986) Intralaminar Fracture in Graphite/Epoxy Laminates. Engineering Fracture Mechanics, 23, 719-733. http://dx.doi.org/10.1016/0013-7944(86)90118-9

[6] Makato, I. and Yashihiro, T. (2001) Fracture Toughness of Spherical Silica-Filled Epoxy Adhe Sives. International Journal of Adhesion and Adhesive, 21, 389-396. http://dx.doi.org/10.1016/S0143-7496(01)00016-1

[7] Wong, K.J., Yousif, B.F. and Low, K.O. (2010) Effects of Fillers on the Fracture Behavior of Par Ticulatepolyester Composites. Journal of Strain Analysis for Engineering Design, 45, 67-78. https://www.researchgate.net/journal/0309-3247 http://dx.doi.org/10.1243/03093247JSA553

[8] Srivastava, V.K., Shembekar, P.S. and Prakash, R. (1998) Fracture Behavior of Fly-Ash Filled FRP Composites. Composite Structure, 10, 271-279. http://dx.doi.org/10.1016/0263-8223(88)90006-2

[9] Shao, Y., Patrick, R., Frank, H. and Klaus, F. (2006) Epoxy Nano Composites-Fracture and Toughening Mechanisms. Engineering Fracture Mechanics, 73, 2375-2398. http://dx.doi.org/10.1016/j.engfracmech.2006.05.018

[10] Liu, Q. and Hughes, M. (2008) The Fracture Behaviour and Toughness of Woven Flax Fiber Reinforced Epoxy Composites. Composites Part A, 39, 1644-1652. http://dx.doi.org/10.1016/j.compositesa.2008.07.008

[11] Leonard, W.H., Low, K.O. and Yousif, K.F. (2009).Fracture Behaviour of Glass Fber-Reinforced Polyester Composite. Journal of Material Science, 83, 223-228.

[12] Pinho, S.T., Robinson, P. and Lannucci, L. (2006) Fracture Toughness of the Tensile and Compressive Fiber Failure Modes in Laminated Composites. Composite Science Technology, 66, 2069-2079. http://dx.doi.org/10.1016/j.compscitech.2005.12.023

[13] Jang, J. and Yang, H. (2000) Toughness Improvement of Carbon Fiber/Polybenzoxazine Composites by Rubber Modification. Composites Science and Technology, 60, 457-463. http://dx.doi.org/10.1016/S0266-3538(99)00146-3

[14] Mostovoy, S. and Riling, E.J. (1966) Fracture Toughness of an Epoxy System. Journal of Applied Polyme Science, 10, 1351-1371. http://dx.doi.org/10.1002/app.1966.070100913

[15] Rys, T.P., Chen, L. and Sanker, B.V. (2004) Mixed Mode Fracture Toughness of Laminated Sitched Composites.

[16] Nishijima, S., Honda, Y. and Okada, Y.T. (1995) Application of the Positron Annihilation Method for Evaluation of Organic Materials for Cryogenic Use. Cryogenics, 35, 779-781. http://dx.doi.org/10.1016/0011-2275(95)90913-Z

[17] Sung, W.K., Jang, K.M. and Yiu, W.M. (1993) Fracture Toughness and Failure Mechanisms in Silica-Filled Epoxy Resin Composites: Effects of Temperature and Loading Rate. Journal of Polymer, 34, 3446-3455. http://dx.doi.org/10.1016/0032-3861(93)90474-O 
[18] Yang, Z. and Zhen, K. (2013) Simultaneous Enhanced Cryogenic Tensile Strength and Fracture Toughness of Epoxyresin by Carboxylic Nitrile-Butadiene Nano-Rubber. Compos: Part A, 55, 178-187. http://dx.doi.org/10.1016/j.compositesa.2013.09.005

[19] Masaya, M., Yasuhide, S., Tomo, T. and Fumio, N. (2012) Interlaminar Fracture Characterization of Wove Glass/Epoxy Composites under Mixed Mode II/III Loading Condition Cryogenic Temperature. Engineering Fracture Mechanics, 96, 615-625. http://dx.doi.org/10.1016/j.engfracmech.2012.09.019

[20] Chang, S.B., Jin, G.K. and Dai, G.L. (2013) Performance Improvement by Glass Fiber of Adhesively Bonded Metal Joints at the Cryogenic Temperature. Composite Structure, 96, 321-331. http://dx.doi.org/10.1016/j.compstruct.2012.08.050

[21] Soon, C.K., Tadaharu, A. and Wakako, A. (2008) Temperature Dependence of Fracture Toughness of Silica/Epoxy Composites. Composites Part B: Engineering, 39, 773-781. http://dx.doi.org/10.1016/j.compositesb.2007.10.008

[22] Magid, B., SaeedZiaee, K.G. and Marcus, S. (2005) The Combined Effects of Load, Moisture and Temperature on the Properties of E-Glass/Epoxy Composites. Composite Structure, 71, 320-326. http://dx.doi.org/10.1016/j.compstruct.2005.09.022

[23] Yong, R.J. and Spanoudakis, J. (1984) Crack Propagation in a Glass Particle Filled Epoxy Resin Effect of Particle Volume Fraction and Size. Journal of Material Science, 19, 473-486. http://link.springer.com/article/10.1007\%2FBF00553571 http://dx.doi.org/10.1007/BF02403234

[24] Hulugappa, B., Suresha, B. and Achutha, M.V. (2016) Effect of Fillers on Mechanical Properties and Fracture Toughness of Glass Fabric Reinforced Epoxy Composites. Journal of Minerals and Materials Characterization and Engineering, 4, 1-14. http://dx.doi.org/10.4236/jmmce.2016.41001

[25] Joao, M. (2012) Effect of Temperature on the Mechanical Properties of Polymer Mortars. Mate Rails Research, 15, 645-649. http://dspace.nitrkl.ac.in/dspace

[26] Gong, M., Wang, X.F. and Zhao, J.H. (2007) Experimental Study on Mechanical Behaviour of Laminates at Low Temperature. Cryogenics, 47, 1-7. http://dx.doi.org/10.1016/j.cryogenics.2006.01.018

[27] Kim, M., kang, S. and Kim, C. (2004) Progressive Failure Analysis of Glass /Epoxy Composite at Low Temperature. Composite Science and Technology, 64, 2353-2362. http://www.ncbi.nlm.nih.gov/pubmed

[28] Moloney, A.C., Kausch, H. and Kaiser, T. (1987) Review-Parameters Determining the Strengthand Toughness of Particulate Filled Epoxy Resins. Journal of Material Science, 22, 381-393. http://dx.doi.org/10.1007/BF01160743

[29] Nakamura, Y., Yamaguchi, Y. and Okubo, M. (1992) Effect of Particle Size on Mechanical and Impact Properties of Epoxy Resin Filled with Spherical Silica. Journal Applied polymer Science, 45, 1281-289. http://dx.doi.org/10.1002/app.1992.070450716

[30] Ma, J., Mo, M.S. Du, X.S. and Rosso, P., Friedrich, K. and Kuan, H.C. (2008) Effect of Inorganic Nanoparticles on Mechanical Property, Fracture Toughness and Toughening Mechanism of Two Epoxy Systems. Polymer, 49, 3510-3523.

http://dx.doi.org/10.1016/j.polymer.2008.05.043

[31] Bhandakkar, A., Kumar, N., Prasad, R.C. and Sastry, M.L. (2014) Interlaminar Fracture Toughness of Epoxy Glass Fiber FAC Laminate Composite. Materials Sciences and Applications, 5, 231-244. http://www.scirp.org/journal

[32] Tripathi, G. and Srivastava, D. (2008) Studies on the Physico-Mechanical and Thermal Characteris Tics of Blends of DGEBA Epoxy, 3,4 Epoxy Cyclohexylmethyl, 3',4'-Epoxycy- 
lohexane Carboxyl Ate and Carboxyl Terminated Butadiene Co-Acrylonitrile (CTBN). Materials Science and Engineering: A, 496, 483-493.

http://dx.doi.org/10.1016/j.msea.2008.06.035

[33] Ashcroft, I.A., Hughes, D.J. and Shaw, S.J. (2001) Mode I Fracture of Epoxy Bonded Composite Joints: 1. Quasi-Static Loading. International Journal of Adhesion and Adhesives, 21, 87-99. http://dx.doi.org/10.1016/S0143-7496(00)00038-5

[34] Kalarikkal, S.G. and Sankar, B.V. (2006) Effect of Cryogenic Temperature on the Fracture Toughness of Graphite Filled Glass Epoxy Composites. Journal Engineering Material and Technology, 128, 151-157. http://dx.doi.org/10.1115/1.2172274

[35] Marom, G. (1989) Environmental Effects on Fracture Mechanical Properties of Polymer Composites. In: Friedrich, K., Ed., Application of Fracture Mechanics to Composite Materials, Elsevier, Amsterdam, 397-424. https://www.elsevier.com/books http://dx.doi.org/10.1016/B978-0-444-87286-9.50014-0

[36] Shen, C. and Springer, S.G. (1977) Environmental Effects on the Elastic Moduli of Composite Materials. Journal of Composite Materials, 11, 250-264.

https://deepblue.lib.umich.edu/handle/2027.42/67725 http://dx.doi.org/10.1177/002199837701100301

[37] Shen, C. and Springer, S.G. (1977) Effects of Moisture and Temperature on the Tensile Strength of Composite Materials. Journal of Composite Materials, 11, 2-16. http://dx.doi.org/10.1177/002199837701100102

[38] Srivastava, V.K. (1998) Moisture Effect on the Toughness, Mode-I and Mode-II of Particles Filled Quasi-Isotropic Glass-Fiber Reinforced Polyester Resin Composites. Journal of Materials Science, 33, 1129-1136. http://dx.doi.org/10.1023/A:1004305104964

[39] Sukjoo, C. and Bhavani, V.S. (2007) Fracture Toughness of Transverse Crack in Graphite/ Epoxy Laminates At Cryogenic Conditions. Composites Part B: Engineering, 38, 193-200. http://dx.doi.org/10.1016/j.compositesb.2006.06.005

\section{Submit or recommend next manuscript to SCIRP and we will provide best service} for you:

Accepting pre-submission inquiries through Email, Facebook, LinkedIn, Twitter, etc. A wide selection of journals (inclusive of 9 subjects, more than 200 journals)

Providing 24-hour high-quality service

User-friendly online submission system

Fair and swift peer-review system

Efficient typesetting and proofreading procedure

Display of the result of downloads and visits, as well as the number of cited articles

Maximum dissemination of your research work

Submit your manuscript at: http://papersubmission.scirp.org/

Or contact msa@scirp.org 